\title{
Genome-Wide Uniparental Disomy and Copy Number Variations in Renal Cell Carcinomas Associated with Birt-Hogg-Dubé Syndrome
}

\author{
Yasuhiro Iribe, ${ }^{*}$ Masahiro Yao, ${ }^{\dagger}$ Reiko Tanaka, ${ }^{\ddagger}$ Naoto Kuroda, ${ }^{\S}$ Yoji Nagashima, ${ }^{\top}$ Yukio Nakatani, $\|$ and Mitsuko Furuya*

\begin{abstract}
From the Departments of Molecular Pathology* and Urology and Molecular Genetics, ${ }^{\dagger}$ Yokohama City University Graduate School of Medicine, Yokohama; the Medical Mycology Research Center ${ }^{\ddagger}$ Chiba University, Chiba; the Department of Diagnostic Pathology, ${ }^{\S}$ Kochi Red Cross Hospital, Kochi; the Department of Surgical Pathology, "Tokyo Women's Medical University, Tokyo; and the Department of Diagnostic Pathology, "Chiba University Graduate School of Medicine, Chiba, Japan
\end{abstract}

\author{
Accepted for publication \\ October 7, 2015. \\ Address correspondence to \\ Mitsuko Furuya, M.D., Ph.D., \\ Department of Molecular \\ Pathology, Yokohama City \\ University Graduate School of \\ Medicine, 3-9 Fukuura, \\ Kanazawa-ku, Yokohama \\ 236-0004, Japan. E-mail: \\ mfuruya@yokohama-cu.ac.jp.
}

\begin{abstract}
Birt-Hogg-Dubé syndrome is an inherited disorder caused by germline mutations of the folliculin gene $(F L C N)$. The affected patients are prone to developing renal cell carcinomas (RCCS). Most mutant FLCNassociated RCCs (mFLCN-RCCs) are histologically chromophobe RCCs and hybrid oncocytic/chromophobe tumors. It is incompletely understood whether mFLCN-RCCs have different chromosomal abnormalities compared with their sporadic histological counterparts. Herein, we describe somatic mutations of FLCN and DNA-copy number abnormalities using a high-density, whole-genome, single-nucleotide polymorphism array. The histological types included chromophobe RCC $(n=12)$, hybrid oncocytic/ chromophobe tumor $(n=5)$, and clear-cell RCC $(n=2)$. Of 19 tumors, 8 had pathological somatic mutations of FLCN. Among $11 \mathrm{mFLCN}$-RCCs investigated by single-nucleotide polymorphism array, 8 showed balanced genomic profiles, 2 had gains in chromosome $3 q$, and 1 had gains in chromosomes $1 q$ and 7. All had copious numbers of loss of heterozygosity in a wide range of chromosomes. The common loss-of-heterozygosity regions were chromosomes 3p24, 8q11, 16q11, Xp22-21, Xp11, Xq11, $X q 13$, and $X q 23$. Most of the loss of heterozygosity was because of uniparental disomy. Common uniparental disomy patterns in chromophobe RCCs and hybrid oncocytic/chromophobe tumors indicated that these types were relatively similar in cytogenetic events. Two clear-cell RCCs also shared several uniparental disomy regions with chromophobe RCCs and hybrid oncocytic/chromophobe tumors. mFLCN-RCCs may have common therapeutic targets among different histological types. (Am J Pathol 2016, 186: 337-346; http://dx.doi.org/10.1016/j.ajpath.2015.10.013)
\end{abstract}

Renal cell carcinoma (RCC) is a life-threatening disease occurring in middle-aged and elderly individuals. Early detection is necessary for curative treatment, especially for individuals who are at genetic risk of RCC. ${ }^{1}$ There are several types of hereditary RCCs, including von-HippelLindau (VHL) disease, hereditary papillary RCC, and hereditary leiomyomatosis and RCC. Birt-Hogg-Dubé syndrome (BHD; alias Hornstein-Knickenberg syndrome) is an inherited disorder characterized by skin fibrofolliculomas, pulmonary cysts, and multiple RCCs. ${ }^{2,3}$ Genetic mutation of the folliculin gene $(F L C N)$, mapped at $17 \mathrm{p} 11.2$, is responsible for this disorder. ${ }^{4}$ Approximately $20 \%$ to $30 \%$ of the individuals with BHD develop RCCs, and most of these tumors are histologically chromophobe RCCs and hybrid oncocytic/ chromophobe tumors (HOCTs). ${ }^{5-7}$ Although the World Health Organization's renal tumor classification does not yet define HOCT, HOCT is proposed as a subtype of

\footnotetext{
Supported by Japan Society for the promotion of Science (JSPS), Grantsin-Aid for Scientific Research 26460422 (M.F.), 26460456 (Y.Nag.), 15K08374 (Y.Nak.), and 15K10600 (M.Y.), Ministry of Health, Labor, and Welfare 1390890034 (Y.Nak.), Yokohama Foundation for Advancement of Medical Science (M.F.), the Mitsubishi Foundation 26329 (M.F.), and the Project for Development of Innovative Research on Cancer Therapeutics (P-DIRECT), Ministry of Education, Culture, Sports, Science, and Technology of Japan (M.Y.).

Disclosures: None declared.
} 
chromophobe RCC. ${ }^{8}$ Clear-cell RCCs and papillary RCCs are less frequently observed in BHD kidney. Herein, we call the RCCs occurring in patients with BHD mutant $F L C N$ associated RCCs ( $\mathrm{m} F L C N$-RCCs).

In sporadic RCCs, each histological type is characterized by abnormal chromosomal copy number profiles. For example, clear-cell RCCs are characterized by losses of chromosomes $3 \mathrm{p}$ and $9 \mathrm{q}$, trisomy 5 , and gains of $5 \mathrm{q}$ and 7. ${ }^{9,10}$ Chromophobe RCCs exhibit frequent losses of chromosomes 1, 2, 6, 10, 13, 17, and 21. ${ }^{11,12}$ Renal oncocytomas show less frequent losses of chromosomes 1 and $\mathrm{Y}$, or rearrangements involving 11q12-q13. ${ }^{13,14}$ A large proportion of renal oncocytomas have balanced genomic profiles. ${ }^{11,15}$ Currently, only a limited amount of information is available regarding chromosomal copy number profiles of mFLCN-RCCs. In a previous study by Klomp et al, ${ }^{16}$ cytogenetic characteristics of six RCCs obtained from BHD patients were described. The tumors had a distal convoluted tubules-derived morphology that resembled sporadic chromophobe RCCs and oncocytomas. Interestingly, none of them shared chromosomal abnormalities that are generally observed in sporadic chromophobe RCCs. The findings suggested that chromophobe RCCs occurring in BHD patients, even though morphologically similar to sporadic ones, are different in molecular background. Unfortunately, limited resolution prevented them from detecting small focal deletions and amplifications. The possible presence of small chromosomal abnormalities characterizing $\mathrm{m} F L C N$-RCC remains unknown.

Herein, we performed copy number variation (CNV) analysis of three histological types of mFLCN-RCCs using a high-density, whole-genome, single-nucleotide polymorphism array. All HOCTs and most chromophobe RCCs demonstrated balanced genomic profiles. A series of segments of loss of heterozygosity ( $\mathrm{LOH})$ common to all tumors (regardless of histological type) was identified in chromosomes 3p, 8q, 16q, Xp, and Xq. Most of the LOH regions were found to exist as uniparental disomy (UPD; alias copyneutral LOH). In UPD regions, one allele was lost, followed by duplication of the remaining allele. UPD was initially described in developmental disorders, and it has also been detected in a variety of malignancies, such as myeloproliferative syndrome and colorectal cancer. ${ }^{17}$ Herein, we describe the chromosomal abnormalities in $\mathrm{m} F L C N$-RCCs characterized by UPD. Potentially activated molecules in the kidney of BHD patients are also discussed.

\section{Materials and Methods}

\section{Samples}

Nineteen $\mathrm{m} F L C N$-RCCs obtained from 10 patients who were diagnosed with BHD by genetic testing were used in the study. Among them, $11 \mathrm{~m} F L C N$-RCCs were used for the chromosomal analysis. Normal renal tissues obtained from BHD patients $(n=11)$ were also used for the quantitative RT-PCR analysis. Tissues were obtained from sporadic groups, clear-cell RCCs $(n=14)$, chromophobe RCCs $(n=11)$, and renal oncocytoma $(n=9)$. In addition, normal kidney tissues of sporadic cases $(n=8)$ were used for comparison. Patients with sporadic renal tumors did not receive genetic testing for $F L C N$, but none had histories of pneumothorax, pulmonary cysts, or fibrofolliculomas. Surgically resected tumor tissues and adjacent normal renal

Table 1 Histology, Prognosis, and Germline and Somatic Mutations of FLCN

\begin{tabular}{|c|c|c|c|c|c|c|}
\hline $\begin{array}{l}\text { Case } \\
\text { no. }\end{array}$ & $\begin{array}{l}\text { Sex/age, } \\
\text { years }\end{array}$ & $\begin{array}{l}\text { Histology } \\
\text { (tumor no.) }\end{array}$ & Stage/grade & $\begin{array}{l}\text { Prognosis } \\
\text { (months) }\end{array}$ & Germline mutation of FLCN & Somatic mutation of FLCN \\
\hline BP1 & $F / 46$ & $\begin{array}{l}\text { HOCT (T1) } \\
\text { and HOCT (T2) }\end{array}$ & $\begin{array}{c}\mathrm{pT} 1 \mathrm{a} / \mathrm{G} 2 \text { and } \\
\mathrm{pT} 1 \mathrm{a} / \mathrm{G} 3\end{array}$ & NED (59) & Exon 5c.332_349del & $\begin{array}{l}\text { Exon 6c.453delGT and exon } \\
\text { 4c.164delC }\end{array}$ \\
\hline BP2 & $F / 68$ & $\begin{array}{l}\text { chRCC (T1) } \\
\text { and HOCT (T2) }\end{array}$ & $\begin{array}{l}\mathrm{pT} 1 \mathrm{a} / \mathrm{G} 2 \text { and } \\
\mathrm{pT} 1 \mathrm{a} / \mathrm{G} 2\end{array}$ & NED (35) & Exon 11c.1285dupC & Undetectable exon 10 c. 1174 delC \\
\hline BP3 & $F / 46$ & $\operatorname{chRCC}(\mathrm{T} 1)$ & $\mathrm{pT} 1 \mathrm{a} / \mathrm{G} 2$ & NED (26) & Exon12c.1429 C>T & Exon11c.1234 delGinsAGA \\
\hline BP6 & $\mathrm{F} / 40$ & $\operatorname{ccRCC}(\mathrm{T} 1)$ & $\mathrm{pT} 1 \mathrm{a} / \mathrm{G} 3$ & NED (24) & Exon 12c. 1347_1353dupCCАСCCT & Undetectable \\
\hline BP7 & $\mathrm{F} / 67$ & $\operatorname{chRCC}(\mathrm{T} 1)$ & $\mathrm{pT} 1 \mathrm{a} / \mathrm{G} 3$ & NED (21) & Exon4c.199dupG & Exon 11c.1285dupC \\
\hline BP8 & $M / 54$ & $\operatorname{chRCC}(\mathrm{T} 1)$ & $\mathrm{pT} 1 \mathrm{a} / \mathrm{G} 2$ & NED (22) & Exon 11c.1285dupC & Undetectable \\
\hline \multirow[t]{4}{*}{ BP9 } & $M / 50$ & $\operatorname{chRCC}(\mathrm{T} 1)$ & $\mathrm{pT} 1 \mathrm{a} / \mathrm{G} 2$ & NED (17) & Exon 13 c.1528delGAG & Exon12c.1383C $>\mathrm{T}$ \\
\hline & & $\operatorname{chRCC}(\mathrm{T} 2)$ & $\mathrm{pT} 1 \mathrm{a} / \mathrm{G} 2$ & & & Undetectable \\
\hline & & HOCT (T6) & $\mathrm{pT} 1 \mathrm{a} / \mathrm{G} 2$ & & & Undetectable \\
\hline & & HOCT (T7) & $\mathrm{pT} 1 \mathrm{a} / \mathrm{G} 2$ & & & Undetectable \\
\hline BP10 & $M / 55$ & $\operatorname{ccRCC}(\mathrm{T} 1)$ & $\mathrm{pT} 3 \mathrm{a} / \mathrm{G} 2$ & NED (5) & Exon 12c. 1347_1353dupCСАСССТ & Exon9c.922G $>\mathrm{T}$ \\
\hline
\end{tabular}

F, female; M, male; ccRCC, clear-cell renal cell carcinoma; chRCC, chromophobe renal cell carcinoma; FLCN, folliculin gene; HOCT, hybrid oncocytic/ chromophobe tumor; LOH, loss of heterozygosity; NED, no evidence of disease. 
tissues were snap frozen and stored in liquid nitrogen until use. Written informed consent for whole genome analysis was obtained from each patient with renal neoplasms. The study design was approved by the Institutional Review Boards of Yokohama City University (Yokohama, Japan) and affiliated hospitals. The remaining renal tissues were fixed with $10 \%$ buffered formalin and embedded in paraffin. Hematoxylin and eosin staining was performed for routine histological diagnosis. Histological types of renal tumors, stages, and Fuhrman nuclear grades were determined by the two pathologists with expertise in renal tumors (N.K. and Y.Nag.).

\section{DNA Isolation and Determination of FLCN Mutations}

To determine germline mutations of FLCN, DNA from peripheral blood leukocytes was obtained using LabPass Blood Mini Kits (Cosmo Genetech, Seoul, Republic of Korea), according to the manufacturer's instructions. To assess possible somatic mutations of FLCN, DNA from renal tumors was obtained using QIAamp DNA Mini Kits (Qiagen, Hilden, Germany), according to the manufacturer's instructions. Exons 4 to 14 of the FLCN gene and exons 1 to
3 of the $V H L$ gene were amplified by PCR using the primers described previously. ${ }^{4,18}$ PCR conditions were described in our previous study. ${ }^{19}$ After purification, DNA was labeled with Big Dye Terminator version 1.1 Cycle Sequencing Kit (Life Technologies, Carlsbad, CA), and DNA sequencing was performed using a sequencer ABI Prism 3100 Genetic Analyzer (Life Technologies). If only the germline mutational signal was amplified and the wild-type sequence was unreadable in the DNA from renal tumor tissue, it was determined that $\mathrm{LOH}$ occurred as the second hit. If a somatic intragenic mutation was suggested in a different region from the genetically mutated site, the PCR product was subcloned and sequenced to clarify the second hit.

\section{CytoScan HD Array and CNV Analysis}

CytoScan HD Array (Affymetrix, Santa Clara, CA) was used to analyze genomic alterations, according to the manufacturer's protocol. This array contains 2.67 million markers. In brief, $250 \mathrm{ng}$ of genomic DNA from mFLCN-RCCs was digested with the restriction enzyme NspI and then ligated to an adapter, followed by PCR amplification. The purified PCR

A

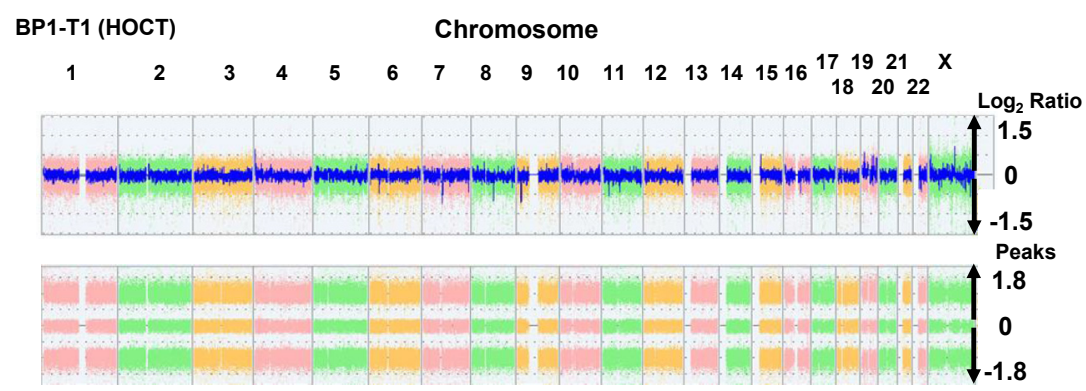

B

BP5-T1 (chRCC)

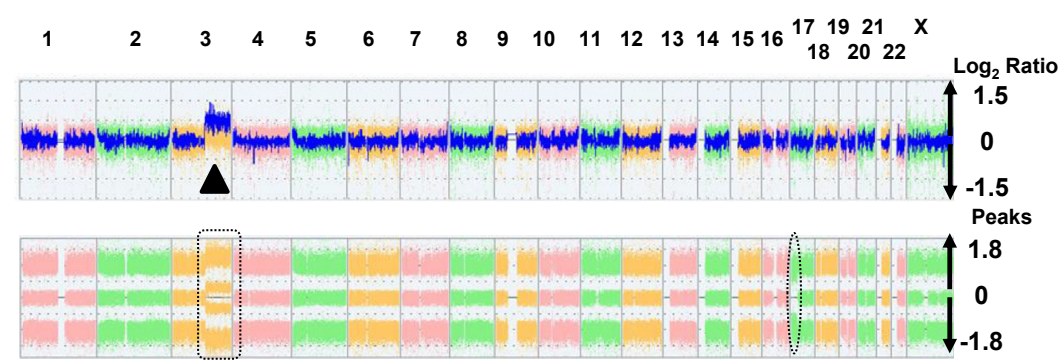

C

BP6-T1 (ccRCC)

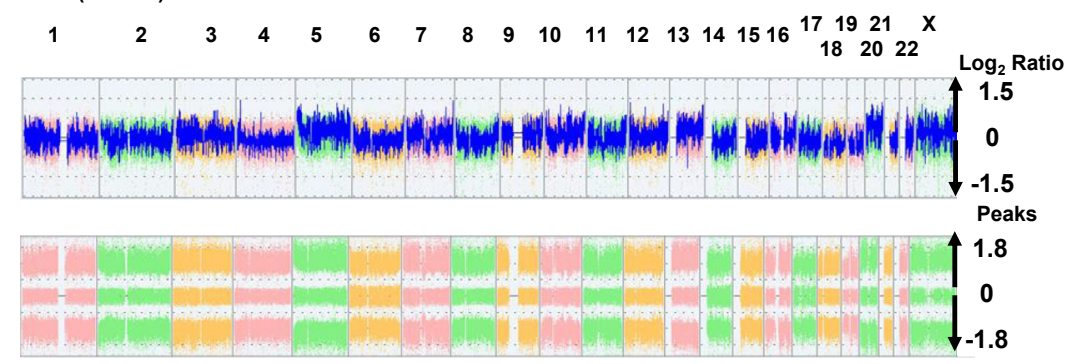

Figure 1 Copy number ratios and allele peaks. Representative examples of copy number ratios [ $\log _{2}$ ratios (top panels)] and allele peaks (bottom panels) of all chromosomes (the left end, chromosome 1; the right end, chromosome $\mathrm{X}$ ) in a hybrid oncocytic/chromophobe tumor (HOCT; A), a chromophobe renal cell carcinoma (chRCC; B), and a clear-cell RCC (cCRCC; C). A: All chromosomes demonstrate balanced copy number ratios and trimodal allele peaks. B: Chromosome $3 q$ shows an increased $\log _{2}$ ratio (arrowhead) and tetramodal allele peaks (dotted rectangle), indicating trisomy. Chromosome 17p demonstrates a normal $\log _{2}$ ratio but bimodal allele peaks (dotted circle), indicating uniparental disomy. C: The $\log _{2}$ ratios are within balanced copy number, but slight mosaic gains in chromosomes 5, 13,20, and $X$ and mosaic losses in chromosomes 18 and 19 are observed. All chromosomes demonstrate trimodal allele peaks. 
products were fragmented, end labeled, and hybridized to the array. Arrays were washed and stained with phycoerythrin using GeneChip Fluidics Station 450 (Affymetrix). Fluorescent signals were scanned using GeneChip Scanner 3000 7G (Affymetrix). Scanned data files were generated using GeneChip Command Console Software version 4 (Affymetrix).

The data so obtained were analyzed using Chromosome Analysis Suite version 3 (Affymetrix) to detect CNV and $\mathrm{LOH}$. Alterations that involved at least 50 markers and were $>400 \mathrm{kbp}$ in length were considered to be CNV. The chromosomal regions that involved at least 50 markers and were $>3 \mathrm{Mb}$ long were considered to be LOH. CNVs of some segments were not assessed because of the lack of available probes for the segments.

The allelic patterns were interpreted as follows. A normal $\log _{2}$ ratio with trimodal allele peaks indicated biparental disomy (normal). A normal $\log _{2}$ ratio with bimodal allele peaks indicated UPD. An increased $\log _{2}$ ratio with tetramodal allele peaks indicated trisomy. A decreased $\log _{2}$ ratio with bimodal allele peaks indicated monosomy.

\section{Quantitative RT-PCR}

Total RNAs from renal frozen tissues were obtained using RNeasy Mini Kit (Qiagen), according to the manufacturer's instructions. QuantiTect SYBR Green PCR Kits (Qiagen) were used for quantitative RT-PCR analysis, according to previously described methods. Conditions for PCR were as follows: $50^{\circ} \mathrm{C}$ for 2 minutes, $95^{\circ} \mathrm{C}$ for 15 minutes, 40 cycles at $95^{\circ} \mathrm{C}$ for 30 seconds, and $60^{\circ} \mathrm{C}$ for 30 seconds. Glyceraldehyde-3-phosphate dehydrogenase (GAPDH) was used as an internal control gene. The primers used for real-time PCR were as follows: human neuropilin/tolloid-like 2 (NETO2), 5'-GGACTGGGATTTCGAGCAAAA-3' (forward) and 5' AGAGCGCACTATTCCATCAGC- $3^{\prime}$ (reverse) ${ }^{20}$; and human GAPDH, $5^{\prime}$-CCACCCATGGCAAATTCC- $3^{\prime}$ (forward) and 5'-TGATGGGATTTCCATTGATGAC-3' (reverse). The
mRNA levels were expressed as the absolute number of copies normalized against GAPDH mRNA. The difference in amplification was determined using the standard curve method.

\section{Statistical Analysis}

Data obtained from quantitative RT-PCR were analyzed using JMP version 11 (SAS Institute, Inc., Cary, NC). The significance of the differences between groups was assessed using the Steel-Dwass test. Differences were considered to be statistically significant at $P<0.05$.

\section{Results}

\section{Histological Information and FLCN Mutation Patterns}

The patients' sex, histological types, stages, Fuhrman nuclear grades, prognosis, genetic mutations, and somatic second-hit mutations of FLCN in each tumor are summarized in Table 1. Clinicopathological information of 9 of 10 patients and 18 of 19 tumors was described in our previous studies. ${ }^{21,22}$ All patients were Japanese (seven females and three males). BP8 is the brother of BP5. One patient had seven tumors, three patients had two tumors, and the other patients had a single tumor. The most frequent tumor type was chromophobe RCC $(n=12)$, followed by HOCT $(n=5)$. There were also two clear-cell RCCs.

Germline mutation analysis revealed that nine patients had frameshift mutations and one patient (BP3) had a nonsense mutation (Table 1). The most frequent mutation pattern was cytosine duplication in the $\mathrm{C}_{8}$ tract in exon 11 (c.1285dupC), which was detected in 4 of 10 patients. Two patients showed sequence repeats (from two to three times) of seven nucleotides in exon 12. The others had different patterns.

Possible somatic mutations of $F L C N$ were investigated (Table 1). The results of some of the tumors were reported

Table 2 Chromosomal Aberrations in mFLCN-RCCs

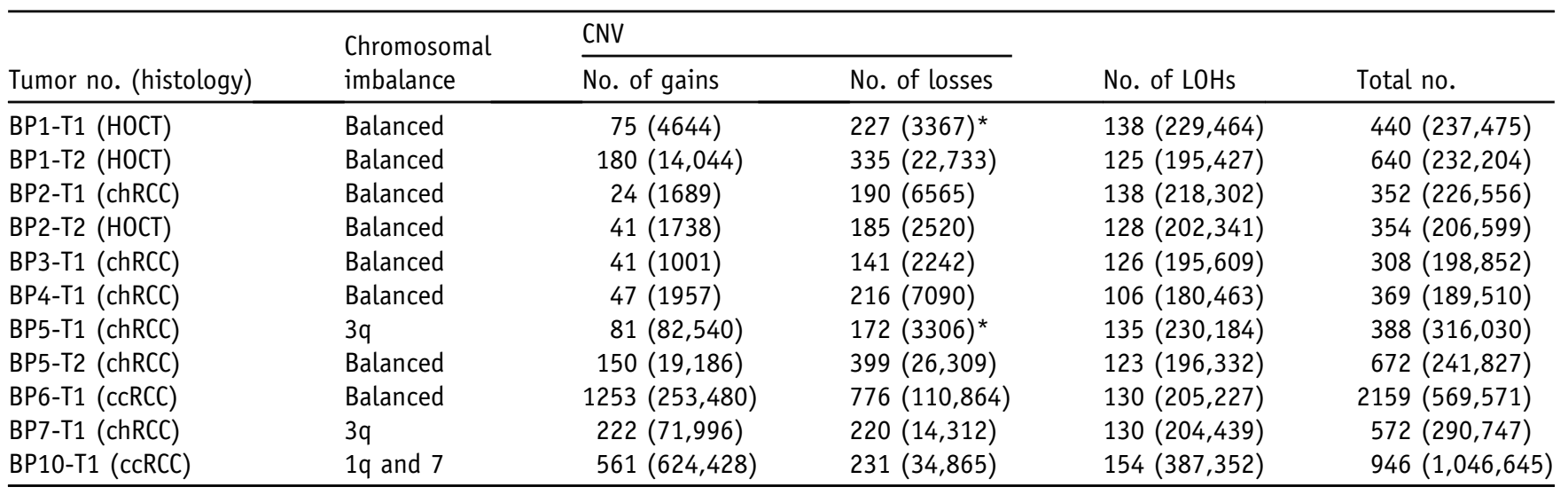

Data in parentheses indicate sum of CNV/LOH size (kbp).

*Focal loss of $17 \mathrm{p} 11.2$ in which FLCN is localized.

cCRCC, clear-cell renal cell carcinoma; chRCC, chromophobe renal cell carcinoma; CNV, copy number variation; HOCT, hybrid oncocytic/chromophobe tumor; $\mathrm{LOH}$, loss of heterozygosity; mFLCN-RCC, mutant folliculin gene renal cell carcinoma. 


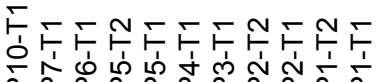

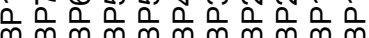
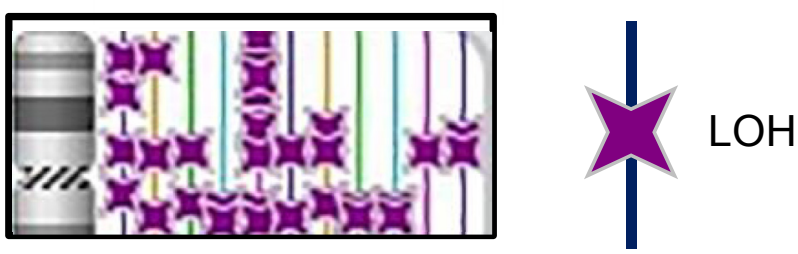

Chr. 1

Chr. 2
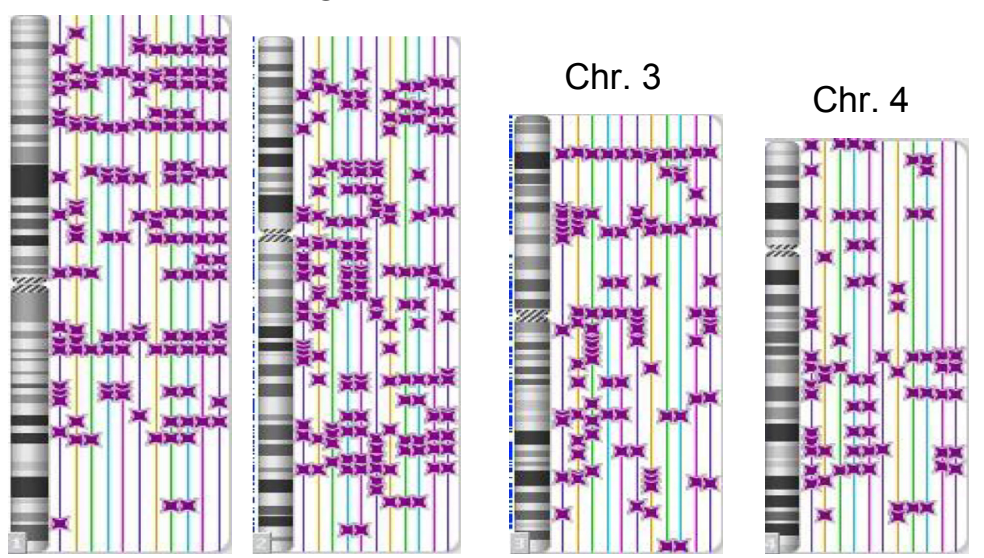

Chr. 5

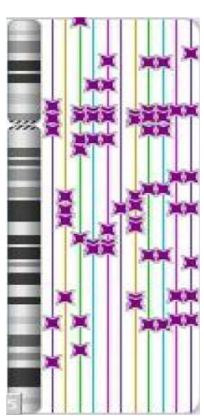

Chr. 6
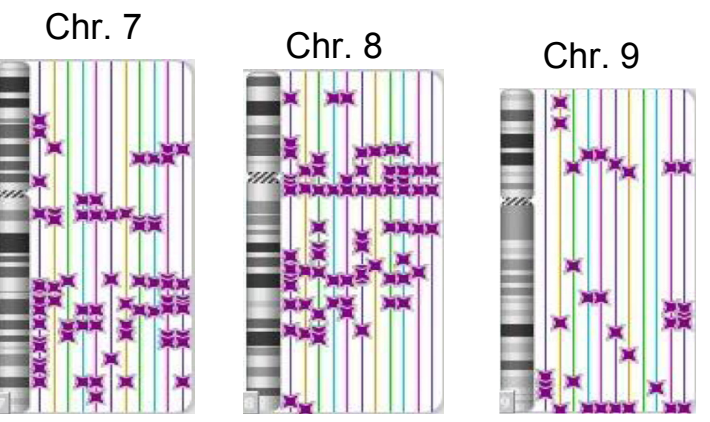

Chr. 10

Chr. 11

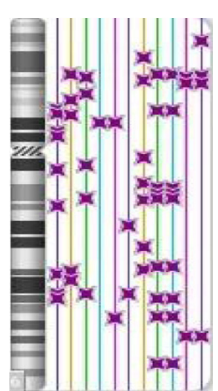

\section{Chr. 13}

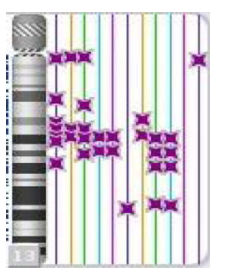

Chr. 14
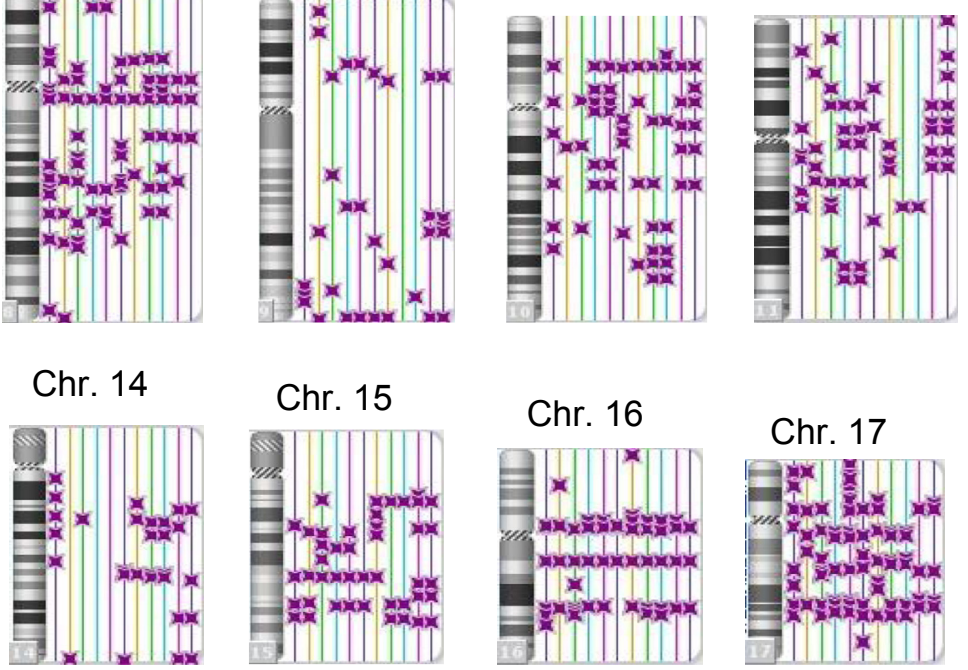

Chr. 12
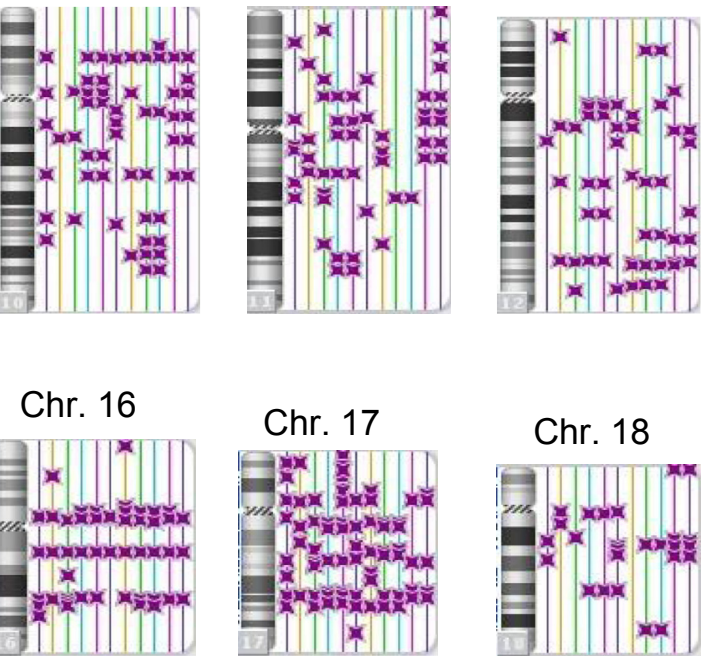

Chr. 17

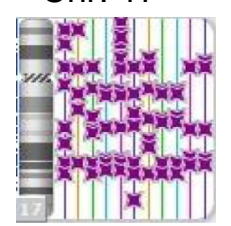

Chr. X
Chr. 18

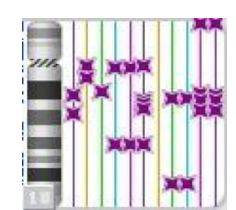

Chr. 19

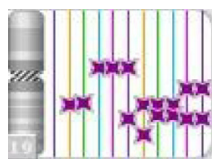

Chr. 20

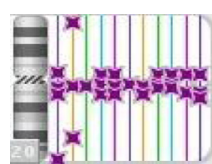

Chr. 21

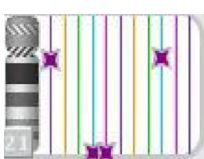

Chr. 22

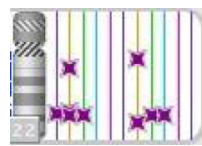

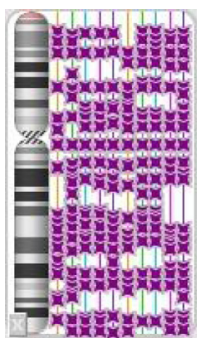

Figure 2 Loss of heterozygosity ( $\mathrm{LOH}$ ) detected by the CytoScan HD Array. Purple stars indicate LOH. Detected LOH regions are presented concurrently (the right end, BP1-T1; the left end, BP10-T1). LOH of all 11 mutant folliculin gene renal cell carcinomas (mFLCN-RCCs) from chromosomes (Chr.) 1 to 22 and of 10 female mFLCN-RCCs from chromosome $\mathrm{X}$ are shown. The histology and FLCN mutations of tumors are described in Table 1. 
in our previous study. ${ }^{22}$ In the present study, somatic mutations amounted to eight tumors and $\mathrm{LOH}$ was detected in one tumor. In one of these tumors (BP9-T1), a single-nucleotide mutation was detected in exon 12 (c.1383C $>\mathrm{T}$ ); however, this alteration did not predict an amino acid change (p.Ser461Ser). In patients who had more than one tumor with a second hit, tumors demonstrated discordant patterns (Table 1). In the other 10 tumors, the second hits were not detected in the $F L C N$ coding exons, as determined by DNA sequencing. Therefore, the copy number status was investigated by quantitative RT-PCR. These 10 RCCs and BP9-T1 demonstrated neither decreased nor increased haploid copy number (data not shown). In two clear-cell RCCs (BP6-T1 and BP10-T1), possible pathological $V H L$ mutations were not detected (data not shown).

\section{Broad Chromosomal Analysis and CNV}

Three HOCTs, six chromophobe RCCs, and two clear-cell RCCs were used for CNV analysis. Ten tumors were obtained from female patients and one tumor was from a male patient. Therefore, chromosome $\mathrm{X}$ was analyzed, excluding the male case, and chromosome Y was not analyzed. All HOCTs and four of six chromophobe RCCs demonstrated broadly balanced chromosomal copy numbers (Figure 1A). The remaining two chromophobe RCCs showed gains in chromosome 3q (BP5-T1 and BP7-T1) (Figure 1B). One of two clear-cell RCCs (BP6-T1) exhibited slight mosaic gains in the short segments of chromosomes 5, 13, 20, and X and mosaic losses in chromosomes 18 and 19 (Figure 1C). The other clear-cell RCC (BP10-T1) showed gains in chromosomes 1q and 7 , and had short segmental gains in $6 \mathrm{p}$ and short segmental losses in 2q, 5q, 10q, 17p, and 19p (data not shown).

The numbers of gains, losses, and $\mathrm{LOH}$ in $11 \mathrm{mFLCN}$ RCCs are summarized in Table 2. HOCTs and chromophobe RCCs had from 24 to 222 copy number gains, and from 141 to 399 copy number losses. The total sizes of gains/losses in these tumor types were from 1001 to 82,540 $\mathrm{kbp}$, whereas those of $\mathrm{LOH}$ were from 180,463 to 230,184 . Two clear-cell RCCs had 1253 and 561 copy number gains, and 776 and 231 copy number losses, respectively.

\section{LOH Analysis}

There were numerous $\mathrm{LOH}$ regions in all samples (Figure 2). Chromosome $\mathrm{X}$ had the highest numbers of $\mathrm{LOH}$ regions (Table 3 ). In addition to common regions shared by all $\mathrm{m} F L C N$-RCCs, $\mathrm{LOH}$ on $1 \mathrm{p} .33$ was detected in 10 tumors (except for BP1-T2). Allele-specific analysis revealed that almost all of the regions with $\mathrm{LOH}$ were diploid (ie, they showed UPD). We investigated the frequency of LOH in chromosome $17 \mathrm{p} 11.2$ in which FLCN is located. Two of $11 \mathrm{mFLCN}$-RCCs (BP1-T1 and BP5-T1) demonstrated segmental $\mathrm{LOH}$ at the $F L C N$-proximal region, whereas the other tumors did not. In BP1, whose germline mutation was detected in exon 5 , a heterozygous mutation pattern was preserved in both BP1-T1 and BP1T2 (data not shown). Sequence analysis detected distinctive somatic mutations in other exons of these tumors (Table 1 and Figure 3, A and B). LOH analysis revealed that the segmental LOH occurred in BP1-T1 but not in $\mathrm{BP} 1-\mathrm{T} 2$, and that the region existed as a mosaic UPD in BP1-T1. With regard to another mFLCN-RCC (BP5-T1) with $\mathrm{LOH}$ in the FLCN locus, we recently reported that the normal $F L C N$ allele was lost. ${ }^{22}$ The current study further revealed that the mutant $F L C N$ allele existed as UPD in this RCC, and was thus homozygous (Figure 3C).

\section{Analysis of NET02 Expression by Quantitative RT-PCR}

UPD in cancer cells can lead to suppression or overexpression of the affected genes. ${ }^{17}$ Among the genes in common UPD regions (Table 3), on the basis of previous

Table 3 Common UPD Regions among mFLCN-RCCs

\begin{tabular}{|c|c|c|}
\hline Chromosome no. & Position & Genes \\
\hline 3 & p24.3 & TBC1D5 \\
\hline 8 & q11.21 & SNTG1 \\
\hline 16 & q11.2 & $\begin{array}{l}\text { ANKRD26P1，SHCBP1, VPS35, ORC6, MYLK3，C16orf87, GPT2, DNAJA2, NET02, ITFG1, PHKB, ABCC12, } \\
\text { ABCC11, MIR548AE2, LONP2 }\end{array}$ \\
\hline$X^{*}$ & p22.13 & PDHA1, MAP3K15, SH3KBP1, CXorf23, LOC729609, MAP7D2, MIR23C, EIF1AX, SCARNA9L, RPS6KA3, CNKSR2 \\
\hline$X^{*}$ & p21.1 & FAM47C, PRRG1, LANCL3, XK, CYBB, DYNLT3 \\
\hline$X^{*}$ & q11.1 & $\begin{array}{l}\text { SPIN4, LOC92249, ARHGEF9, MIR1468, FAM123B, ASB12, MTMR8, ZC4H2, ZC3H12B, LAS1L, FRMD8P1, MSN, } \\
\quad \text { MIR223, VSIG4, HEPH, EDA2R, AR, OPHN1 }\end{array}$ \\
\hline$X^{*}$ & q13.2 & $\begin{array}{l}\text { CHIC1, TSIX, XIST, JPX, FTX, MIR421, MIR374B, MIR374C, MIR545, MIR374A, ZCCHC13, SLC16A2, RLIM, } \\
\text { KIAA2022, ABCB7, UPRT }\end{array}$ \\
\hline$X^{*}$ & q23 & RGAG1, TDGF1P3, CHRDL1, PAK3, CAPN6, DCX, RNU6-28, DKFZp686D0853, ALG13, TRPC5, TRPC50S, ZCCHC16 \\
\hline
\end{tabular}

*The data of chromosome $X$ were composed of 10 female cases, excluding the data from a male case (BP10-T1).

$\mathrm{m} F L C N-R C C$, mutant folliculin gene renal cell carcinoma; UPD, uniparental disomy. 
A

BP1-T1

Germline Mutation FLCN Exon 5

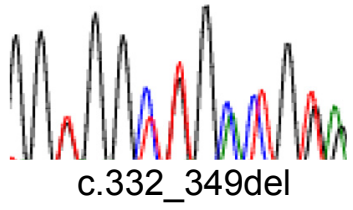

B

BP1-T2

Germline Mutation
FLCN Exon 5

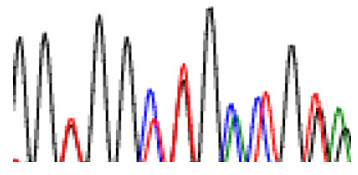

c.332_349del

\section{\begin{tabular}{lll|l|ll} 
Chr.17 & p13.3 & p13.2 & p13.1 & p12 & $17 p 11.2$
\end{tabular}}

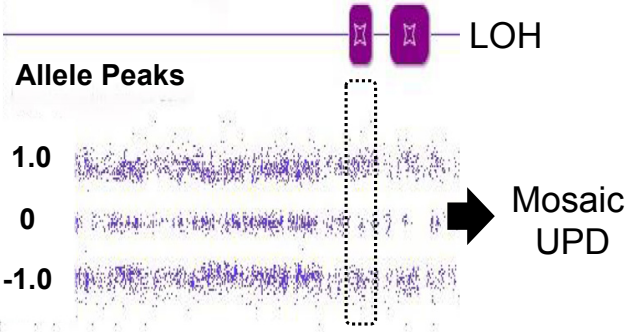

Somatic Event FLCN Exon 6

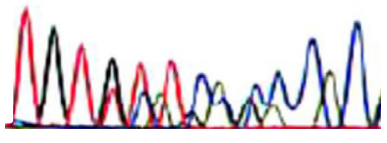

c.453delGT

\section{Somatic Event FLCN Exon 4}

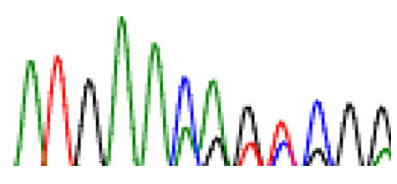

c.164delC

C

BP5-T1

Germline Mutation FLCN Exon 11

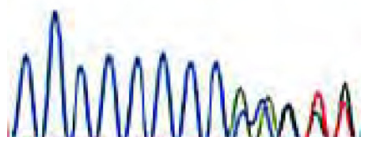

c.1285dupC Heterozygous

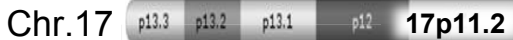
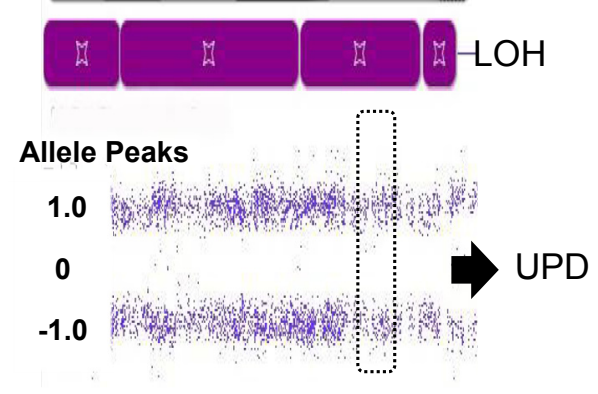

Somatic Event FLCN Exon 11

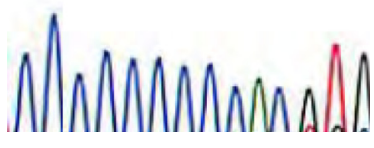

c. 1285 dupC Homozygous

Figure 3 Comparative analysis of folliculin gene (FLCN) mutations and loss of heterozygosity (LOH) in chromosome (Chr.) 17p11.2. Representative analyses of genetic and somatic FLCN mutations, and corresponding chromosomal regions with allele peaks. A and B: Patient BP1 has germline mutation in exon 5 (left sequences). $L O H$ of the FLCN-proximal segment is detected in T1 (A) but not in T2 (B) (middle, purple stars). Allele peaks in the FLCN-proximal segment of T1 demonstrate a trimodal pattern (middle, dotted rectangle in A), indicating mosaic uniparental disomy (UPD). Differential somatic mutations are detected in T1 and T2 (right sequences). C: Patient BP5 has a germline mutation in exon 11 (left sequence). Long LOH segments, including the FLCN proximal region, are detected in chromosome 17p. Allele peaks in the segments demonstrate a bimodal pattern (middle, dotted rectangle), indicating UPD. In $\mathrm{T} 1$, a $\mathrm{C}_{8}$ tract is almost completely replaced by a $\mathrm{C}_{9}$ tract (right sequence). $\mathrm{BD}$, biparental disomy.

studies of RCC-related genes, only one gene, NETO2 at $16 \mathrm{q} 11.2$, was reported as an up-regulated gene in sporadic clear-cell RCCs. ${ }^{20,23}$ To understand whether the known RCC-associated gene in the UPD region demonstrates a differential expression pattern depending on germline mutations of $F L C N$, we compared NETO2 mRNA expression in $\mathrm{m} F L C N$-RCCs, sporadic tumors, and normal kidneys. Two mFLCN-RCCs (BP2-T1 and BP6-T1) demonstrated aberrantly high expression (194 and 176 times higher compared with GAPDH, respectively); thus, the cases were excluded from comparison. NETO2 was up-regulated in $17 \mathrm{~m} F L C N$-RCCs composed of 5 HOCTs, 1 clear-cell RCC, and 11 chromophobe RCCs compared with normal control kidneys $(P=0.002)$ (Figure 4). Sporadic clear-cell RCCs also showed increased levels of NETO2, which was consistent with previous reports. ${ }^{20,23}$ A statistically significant difference between $\mathrm{m} F L C N$ RCCs and other histological types of sporadic tumors was not found. Interestingly, normal kidneys of BHD patients showed higher expression of NETO2 compared with normal control kidneys, which was statistically significant $(P=0.008)$. 


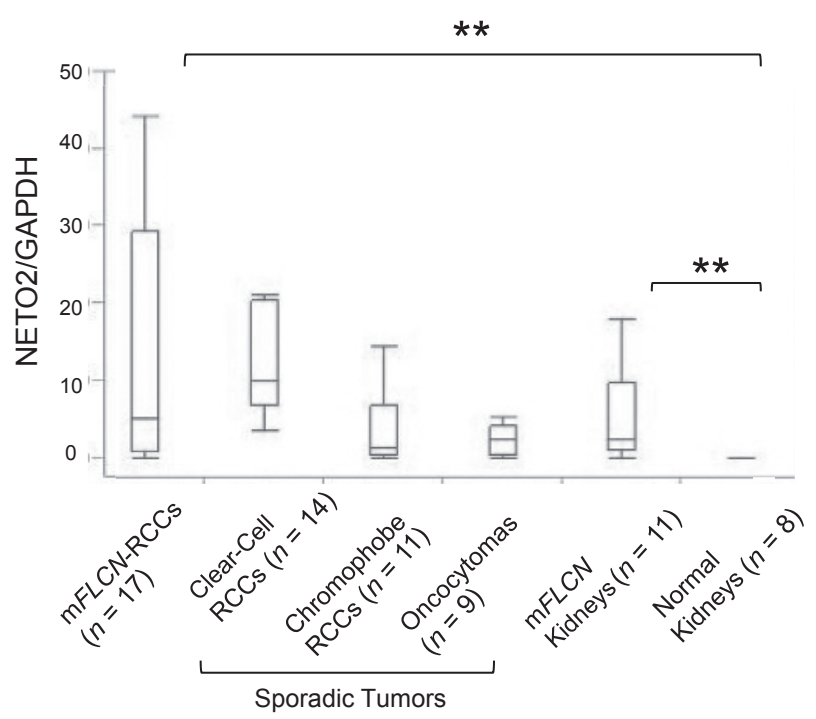

Figure 4 Expression levels of neuropilin/tolloid-like 2 (NETO2) mRNA in tumors and normal kidneys of Birt-Hogg-Dubé and sporadic cases. Sporadic clear-cell renal cell carcinomas (RCCs) demonstrate the highest level of NET02, followed by mutant folliculin gene renal cell carcinomas ( $\mathrm{mFLCN}$ RCCs). mFLCN-RCCs and normal kidneys with germline mutations of FLCN ( $\mathrm{mFLCN}$ kidneys) express significantly higher levels of NETO2 compared with normal kidneys of sporadic cases. ${ }^{* *} P<0.01$. GAPDH, glyceraldehyde-3phosphate dehydrogenase.

\section{Discussion}

A series of genomic studies of renal neoplasms has revealed distinctively different chromosomal profiles and affected cell types of the nephron, according to histological types. Chromophobe RCCs are assumed to arise from distal regions of the nephron, and most of them demonstrate frequent copy number losses in several chromosomes. ${ }^{12}$ Clear-cell RCCs originate in more proximal regions of the nephron, and are characterized by specific exonic somatic mutations, $3 \mathrm{p}$ loss, and $5 \mathrm{q}$ gain. ${ }^{10}$ In the present study, assessment by high-resolution single-nucleotide polymorphism array allowed us to detect many segmental LOH regions in a wide range of chromosomes in $\mathrm{m} F L C N$-RCCs. Most of the LOH regions were revealed to be UPD, and there were many UPD regions common to all three histological types, including two clear-cell RCCs. The presence of UPD was reported in several types of malignancies ${ }^{17,24,25}$; however, the frequency of UPD in solid tumors is not usually high, and genome-wide UPD was not reported in renal tumors. A few clear-cell and papillary RCCs and synchronous tumors were reported to have UPDs in a limited region involving one or a few chromosomes. ${ }^{26-28}$ Therefore, a series of UPDs common to all investigated tumors $(n=11)$ (Table 3$)$ will likely constitute cytogenetic markers distinguishing $\mathrm{m} F L C N$ RCCs from sporadic renal tumors. It remains unknown whether BHD kidneys acquire these chromosomal abnormalities during progressive stages of carcinogenesis or whether normal-looking kidneys already possess specific
UPDs under physiological conditions. It was not possible to perform chromosomal analysis in nontumor BHD kidneys because of its high costs. It is a subject for future studies to clarify possible cytogenetic events occurring in nontumor BHD kidneys.

The previous genomic analysis by Klomp et $\mathrm{a}^{16}$ using six $\mathrm{m} F L C N$-RCCs had demonstrated balanced chromosomal status without apparent loss of chromosome $17 \mathrm{p}$. In the present study, 8 of $11 \mathrm{~m} F L C N$-RCCs demonstrated balanced chromosomal status, 2 chromophobe RCCs showed gains in chromosome 3q, and 1 clear-cell RCC had gains in chromosomes 1q and 7 . The results supported the previous findings that $\mathrm{m} F L C N$-RCCs have distinctively different cytogenetic characteristics from those of sporadic counterparts. Although current World Health Organization classification does not place $\mathrm{m} F L C N-\mathrm{RCC}$ as a distinctive subtype, further investigation will help us establish diagnostic criteria of $\mathrm{m} F L C N-\mathrm{RCC}$. A close analysis of $17 \mathrm{p}$ in which the $F L C N$ gene is localized revealed that most of the $\mathrm{m} F L C N$-RCCs were devoid of $17 \mathrm{p}$ loss, and that two tumors demonstrated segmental UPD in 17p11.2 (Table 2 and Figure 3). Together with the second hit analysis, the frequency of FLCN LOH seems to be low, if any. Most of the $\mathrm{m} F L C N$-RCCs are likely to develop either with small somatic mutations or without the second hits of FLCN.

Acquired UPD indicates genomic instability of the affected regions, leading to inactivation or activation of the involved genes. ${ }^{17}$ The NETO2 gene encodes an auxiliary subunit of the synaptic kainate receptor, and it modulates the channel properties of recombinant and native kainate receptors. ${ }^{29,30}$ Although detailed roles of NETO2 in human diseases are not well characterized, it has been reported to be up-regulated in sporadic clear-cell RCCs and is thought to be a biomarker in highly vascular neoplasms, such as infantile hemangiomas and hepatocellular carcinomas. ${ }^{31,32}$ In this study, the expression level of NETO2 mRNA was the highest in sporadic clear-cell RCCs, which was consistent with a previous study. ${ }^{20,23}$ We found that NETO2 mRNA was apparently higher in normal BHD kidneys than in normal controls (Figure 4). The up-regulation of NETO2 mRNA in these nontumor areas might be associated with a predisposition of BHD kidneys for multiple tumors. The possibility that UPDs of the NETO2 gene already occur in nonneoplastic kidney cannot be excluded. Other possibilities include microscopic preneoplastic lesions in normallooking BHD kidneys. Even though we histologically confirmed that neoplastic lesions were not included in normal areas, the possible presence of microscopic oncocytosis and/or a few atypical tubules in the normal area might contribute to the up-regulation of NETO2. Further studies will clarify the significance of dysregulated NETO2 in the carcinogenesis of BHD kidneys.

In the present study, two clear-cell RCCs showed balanced chromosomes at $3 p$ with wild-type $V H L$. The segmental LOH was not detectable at 3p25.3 in which $V H L$ is located, either. Although the investigated cases are limited 
in number, the present two RCCs seem to develop without mutation/deletion of VHL. We had confirmed positive immunostaining for CA-IX and negative staining for CK7 and CD82, which is consistent with the characteristics of typical clear-cell RCC. ${ }^{21}$ A previous study by Pavlovich et $\mathrm{al}^{6}$ demonstrated that two of eight clear-cell RCCs from BHD patients whose $F L C N$ mutation patterns were not available had $3 \mathrm{p} \mathrm{LOH}$ and missense mutations of $V H L$. In the present study, two clear-cell RCCs shared a series of UPDs with HOCTs and chromophobe RCCs, despite a distinctive immunostaining pattern. Because chromosomes of these clearcell RCCs were more abundant in CNV regions and sizes, this type of tumor might have acquired additional genomic events on the basis of the common cytogenetic abnormalities of those in HOCTs and chromophobe RCCs.

Patients with BHD have high risks of developing multiple RCCs. Discordant second hit patterns in patients who had more than one tumor supported the notion that $\mathrm{m} F L C N$ RCCs occur in an independent manner. ${ }^{33}$ Genome-wide UPD will characterize, in part, the unique features of $\mathrm{m} F L C N$-RCCs. The results indicate that $\mathrm{m} F L C N$-RCCs might have common therapeutic targets regardless of histological types. Not only $\mathrm{m} F L C N$-RCCs but also normallooking renal tissues in individuals with BHD potentially activate some genes that favor carcinogenesis. Further studies are needed to clarify the detailed mechanisms of the carcinogenic switch in renal cells in the setting of haploinsufficient $F L C N$.

\section{Acknowledgments}

We thank Drs. Hiroko Gotoda, Toshiharu Sakuma, Muneyuki Hiraishi, and Akinori Iba for providing clinical information and renal tissues; and Hiromi Soeda, Yuka Imanishi, and Masato Kawashima for excellent assistance.

\section{References}

1. Linehan WM, Srinivasan R, Schmidt LS: The genetic basis of kidney cancer: a metabolic disease. Nat Rev Urol 2010, 7:277-285

2. Menko FH, van Steensel MA, Giraud S, Friis-Hansen L, Richard S, Ungari S, Nordenskjold M, Hansen TV, Solly J, Maher ER: BirtHogg-Dube syndrome: diagnosis and management. Lancet Oncol 2009, 10:1199-1206

3. Toro JR, Wei MH, Glenn GM, Weinreich M, Toure O, Vocke C, Turner M, Choyke P, Merino MJ, Pinto PA, Steinberg SM, Schmidt LS, Linehan WM: BHD mutations, clinical and molecular genetic investigations of Birt-Hogg-Dube syndrome: a new series of 50 families and a review of published reports. J Med Genet 2008, 45:321-331

4. Nickerson ML, Warren MB, Toro JR, Matrosova V, Glenn G, Turner ML, Duray P, Merino M, Choyke P, Pavlovich CP, Sharma N, Walther M, Munroe D, Hill R, Maher E, Greenberg C, Lerman MI, Linehan WM, Zbar B, Schmidt LS: Mutations in a novel gene lead to kidney tumors, lung wall defects, and benign tumors of the hair follicle in patients with the Birt-Hogg-Dube syndrome. Cancer Cell 2002, 2: $157-164$

5. Zbar B, Alvord WG, Glenn G, Turner M, Pavlovich CP, Schmidt L, Walther M, Choyke P, Weirich G, Hewitt SM, Duray P, Gabril F,
Greenberg C, Merino MJ, Toro J, Linehan WM: Risk of renal and colonic neoplasms and spontaneous pneumothorax in the Birt-HoggDube syndrome. Cancer Epidemiol Biomarkers Prev 2002, 11: 393-400

6. Pavlovich CP, Walther MM, Eyler RA, Hewitt SM, Zbar B, Linehan WM, Merino MJ: Renal tumors in the Birt-Hogg-Dube syndrome. Am J Surg Pathol 2002, 26:1542-1552

7. Houweling AC, Gijezen LM, Jonker MA, van Doorn MB, Oldenburg RA, van Spaendonck-Zwarts KY, Leter EM, van Os TA, van Grieken NC, Jaspars EH, de Jong MM, Bongers EM, Johannesma PC, Postmus PE, van Moorselaar RJ, van Waesberghe JH, Starink TM, van Steensel MA, Gille JJ, Menko FH: Renal cancer and pneumothorax risk in Birt-Hogg-Dube syndrome: an analysis of 115 FLCN mutation carriers from 35 BHD families. Br J Cancer 2011, 105 : 1912-1919

8. Srigley JR, Delahunt B, Eble JN, Egevad L, Epstein JI, Grignon D, Hes O, Moch H, Montironi R, Tickoo SK, Zhou M, Argani P: The International Society of Urological Pathology (ISUP) Vancouver Classification of Renal Neoplasia. Am J Surg Pathol 2013, 37: $1469-1489$

9. Hagenkord JM, Gatalica Z, Jonasch E, Monzon FA: Clinical genomics of renal epithelial tumors. Cancer Genet 2011, 204:285-297

10. Cancer Genome Atlas Research Network: Comprehensive molecular characterization of clear cell renal cell carcinoma. Nature 2013, 499: $43-49$

11. Brunelli M, Eble JN, Zhang S, Martignoni G, Delahunt B, Cheng L: Eosinophilic and classic chromophobe renal cell carcinomas have similar frequent losses of multiple chromosomes from among chromosomes 1,2,6,10, and 17, and this pattern of genetic abnormality is not present in renal oncocytoma. Mod Pathol 2005, 18:161-169

12. Davis CF, Ricketts CJ, Wang M, Yang L, Cherniack AD, Shen H, et al: The somatic genomic landscape of chromophobe renal cell carcinoma. Cancer Cell 2014, 26:319-330

13. Yusenko MV, Kuiper RP, Boethe T, Ljungberg B, van Kessel AG, Kovacs G: High-resolution DNA copy number and gene expression analyses distinguish chromophobe renal cell carcinomas and renal oncocytomas. BMC Cancer 2009, 9:152

14. Lindgren V, Paner GP, Omeroglu A, Campbell SC, Waters WB, Flanigan RC, Picken MM: Cytogenetic analysis of a series of 13 renal oncocytomas. J Urol 2004, 171:602-604

15. Durinck S, Stawiski EW, Pavia-Jimenez A, Modrusan Z, Kapur P, Jaiswal BS, et al: Spectrum of diverse genomic alterations define nonclear cell renal carcinoma subtypes. Nat Genet 2015, 47:13-21

16. Klomp JA, Petillo D, Niemi NM, Dykema KJ, Chen J, Yang XJ, Saaf A, Zickert P, Aly M, Bergerheim U, Nordenskjold M, Gad S, Giraud S, Denoux Y, Yonneau L, Mejean A, Vasiliu V, Richard S, MacKeigan JP, Teh BT, Furge KA: Birt-Hogg-Dube renal tumors are genetically distinct from other renal neoplasias and are associated with up-regulation of mitochondrial gene expression. BMC Med Genomics 2010, 3:59

17. Tuna M, Knuutila S, Mills GB: Uniparental disomy in cancer. Trends Mol Med 2009, 15:120-128

18. Yoshida M, Ashida S, Kondo K, Kobayashi K, Kanno H, Shinohara N, Shitara N, Kishida T, Kawakami S, Baba M, Yamamoto I, Hosaka M, Shuin T, Yao M: Germ-line mutation analysis in patients with von Hippel-Lindau disease in Japan: an extended study of 77 families. Jpn J Cancer Res 2000, 91:204-212

19. Furuya M, Tanaka R, Koga S, Yatabe Y, Gotoda H, Takagi S, Hsu YH, Fujii T, Okada A, Kuroda N, Moritani S, Mizuno H, Nagashima Y, Nagahama K, Hiroshima K, Yoshino I, Nomura F, Aoki I, Nakatani Y: Pulmonary cysts of Birt-Hogg-Dube syndrome: a clinicopathologic and immunohistochemical study of 9 families. Am J Surg Pathol 2012, 36:589-600

20. Zaravinos A, Pieri M, Mourmouras N, Anastasiadou N, Zouvani I, Delakas D, Deltas C: Altered metabolic pathways in clear cell renal cell carcinoma: a meta-analysis and validation study focused on the deregulated genes and their associated networks. Oncoscience 2014, 1:117-131 
21. Iribe Y, Kuroda N, Nagashima Y, Yao M, Tanaka R, Gotoda H, Kawakami F, Imamura Y, Nakamura Y, Ando M, Araki A, Matsushima J, Nakatani Y, Furuya M: Immunohistochemical characterization of renal tumors in patients with Birt-Hogg-Dube syndrome. Pathol Int 2015, 65:126-132

22. Furuya M, Hong SB, Tanaka R, Kuroda N, Nagashima Y, Nagahama K, Suyama T, Yao M, Nakatani Y: Distinctive expression patterns of glycoprotein non-metastatic B and folliculin in renal tumors in patients with Birt-Hogg-Dube syndrome. Cancer Sci 2015, 106:315-323

23. Jones J, Otu H, Spentzos D, Kolia S, Inan M, Beecken WD, Fellbaum C, Gu X, Joseph M, Pantuck AJ, Jonas D, Libermann TA: Gene signatures of progression and metastasis in renal cell cancer. Clin Cancer Res 2005, 11:5730-5739

24. Andersen CL, Wiuf C, Kruhoffer M, Korsgaard M, Laurberg S, Orntoft TF: Frequent occurrence of uniparental disomy in colorectal cancer. Carcinogenesis 2007, 28:38-48

25. Tuna M, Ju Z, Smid M, Amos CI, Mills GB: Prognostic relevance of acquired uniparental disomy in serous ovarian cancer. Mol Cancer 2015, 14:29

26. Toma MI, Grosser M, Herr A, Aust DE, Meye A, Hoefling C, Fuessel S, Wuttig D, Wirth MP, Baretton GB: Loss of heterozygosity and copy number abnormality in clear cell renal cell carcinoma discovered by high-density affymetrix $10 \mathrm{~K}$ single nucleotide polymorphism mapping array. Neoplasia 2008, 10:634-642

27. Monzon FA, Alvarez K, Gatalica Z, Bridge JA, Nelson M, Kim HJ, Hagenkord JM: Detection of chromosomal aberrations in renal tumors: a comparative study of conventional cytogenetics and virtual karyotyping with single-nucleotide polymorphism microarrays. Arch Pathol Lab Med 2009, 133:1917-1922
28. Quiroga-Garza G, Pina-Oviedo S, Cuevas-Ocampo K, Goldfarb R, Schwartz MR, Ayala AG, Monzon FA: Synchronous clear cell renal cell carcinoma and tubulocystic carcinoma: genetic evidence of independent ontogenesis and implications of chromosomal imbalances in tumor progression. Diagn Pathol 2012, 7:21

29. Tomita S, Castillo PE: Neto1 and Neto2: auxiliary subunits that determine key properties of native kainate receptors. J Physiol 2012 590:2217-2223

30. Zhang W, St-Gelais F, Grabner CP, Trinidad JC, Sumioka A, Morimoto-Tomita M, Kim KS, Straub C, Burlingame AL, Howe JR, Tomita S: A transmembrane accessory subunit that modulates kainatetype glutamate receptors. Neuron 2009, 61:385-396

31. Calicchio ML, Collins T, Kozakewich HP: Identification of signaling systems in proliferating and involuting phase infantile hemangiomas by genome-wide transcriptional profiling. Am J Pathol 2009, 174: $1638-1649$

32. Villa E, Critelli R, Lei B, Marzocchi G, Camma C, Giannelli G, Pontisso P, Cabibbo G, Enea M, Colopi S, Caporali C, Pollicino T, Milosa F, Karampatou A, Todesca P, Bertolini E, Maccio L, MartinezChantar ML, Turola E, Del Buono M, De Maria N, Ballestri S, Schepis F, Loria P, Enrico Gerunda G, Losi L, Cillo U: Neoangiogenesis-related genes are hallmarks of fast-growing hepatocellular carcinomas and worst survival. Results from a prospective study. Gut 2015, [Epub ahead of print] doi:10.1136/gutjnl-2014-308483.

33. Vocke CD, Yang Y, Pavlovich CP, Schmidt LS, Nickerson ML, Torres-Cabala CA, Merino MJ, Walther MM, Zbar B, Linehan WM: High frequency of somatic frameshift BHD gene mutations in BirtHogg-Dube-associated renal tumors. J Natl Cancer Inst 2005, 97: 931-935 